\title{
Quantifying the importance of different contagion channels as sources of systemic risk
}

\section{Christoph Siebenbrunner ${ }^{1}$}

Received: 31 August 2018 / Accepted: 5 March 2020 / Published online: 23 March 2020

(c) The Author(s) 2020

\begin{abstract}
A framework that allows computing contagion effects from both direct exposure contagion and overlapping portfolios is presented. The effects of the latter are broken down into loss correlation, effects from fire sales and mark-to-market accounting. The impact can be quantified for any single contagion channel as well as when multiple channels are jointly active. The model can be used to compute contagion losses that are consistent with a given macroeconomic scenario and thus provides a macroprudential extension for microprudential stress tests. Empirical results for a real-world banking system suggest that contagion effects stemming from direct exposures have the highest loss contribution.
\end{abstract}

Keywords Systemic risk · Financial contagion - Stress testing

JEL Classification $210 \cdot \mathrm{G} 280 \cdot \mathrm{C} 6$

\section{Introduction}

The financial crisis which started in 2008, in particular the events following the collapse of the investment bank Lehman Brothers, has shown that interconnectivity creates risks for financial stability. In today's highly interconnected financial systems, shocks can spread from single entities to the entire system. While such interconnections may serve as a technique for spreading risk, they can also lead to contagion effects that threaten the stability of the financial system. Such contagion effects may occur via different channels. In this paper, I will study the channels of direct contagion and overlapping portfolios in greater detail.

The goal of this paper is to provide a quantitative framework for computing systemic contagion losses in a financial system, taking into account multiple channels of

Christoph Siebenbrunner

christoph.siebenbrunner@maths.ox.ac.uk

1 Mathematical Institute, University of Oxford, Andrew Wiles Building, Radcliffe Observatory Quarter, Woodstock Road, Oxford OX2 6GG, UK 
contagion. This is important since stress tests, the most prominent form of financial stability analyses, still do not account for such systemic feedback effects. Stress tests have become an important tool for central bank policy makers and supervisors when assessing the capital adequacy of major banks. Major international exercises by the Federal Reserve (DFAST 2019), the European Banking Authority (EBA 2019) and the Bank of England (BoE 2019), however, still conduct stress tests as a mainly 'microprudential' exercise. Under this approach, the financial health of several banks under a stress scenario is assessed by looking at the impact of a stress scenario on each bank in isolation.

Microprudential stress tests have proven to be very useful tools in navigating the financial crisis. But they are not designed to identify risks which stem from interconnections within the banking system. The goal of this paper is to provide a framework that allows computing contagion losses that are consistent with a macroeconomic stress scenario. The output of the model presented in this paper can thus be used as a 'macroprudential' extension module for a microprudential stress test that accounts for systemic feedback effects stemming from the first-round macroeconomic shock to the financial system. Early applications of such a model with only one contagion channel in a stress test can be found in Elsinger et al. (2006) and Feldkircher et al. (2013). The model presented in this paper significantly extends this approach to include multiple contagion channels.

I will further present a framework for ranking the importance of different contagion channels. This is useful for policymakers when defining regulations aimed at reducing systemic risk, such as the the capital buffer requirement for systemically important institutions (EBA 2014). Being able to quantify through which channels a given bank contributes to systemic risk allows for better targeted regulations.

\section{Literature review}

Much of the research on financial stability builds on the seminal contribution of Diamond and Dybvig (1983), who provide an economic explanation for the rationality of bank runs. In their model, a bank cannot observe ex-ante the liquidity preferences of their depositors when deciding where to allocate deposits received. This means that when there is a liquidity shock, as for instance when depositors wish to withdraw more funds than the bank has liquid assets, the bank has to start liquidating long-term assets at a discount. This in turn means that there will not be enough funds anymore to repay all deposits in full; hence, it becomes rational for depositors to participate in a bank run and try to withdraw a maximum amount of savings as early as possible. However, such dynamics were not at the heart of the financial crisis, arguably because wellfunctioning deposit insurance schemes had already been in place in most countries at the beginning of the crisis [which is the solution to this dilemma that Diamond and Dybvig (1983) suggest in their paper]. Hence, other channels of transmission have to be considered for investigating the dynamics of the 2008 crisis.

Allen and Gale (2000) extend the model of Diamond and Dybvig (1983) by including banks in four regions, which are interconnected via interbank loans. In their model, contagion occurs when a shock (a bank run equilibrium) in one region spreads to other regions through the default on interbank loans, which can render institutions in a 
healthy region that are exposed to institutions in the defaulted region insolvent. Allen and Gale (2000) study two possible network configurations, a complete and a ringshaped network, and conclude that the ring-shaped network has a lower probability of contagion because banks are more diversified. Other early contributions include Freixas et al. (2000), who show that - for a given network structure - the extent of contagion strongly depends on the specific parameters of the model, Angelini et al. (1996) and Rochet and Tirole (1996). Heider et al. (2015) develop a model in a similar spirit to Allen and Gale (2000) that accounts for market liquidity of commonly held assets as well.

In order to link the network structure of the interbank market to systemic risk, a mechanism to assess the probability of contagion under given network structures is needed. Eisenberg and Noe (2001) provide such a contagion algorithm, which also forms the basis of the model introduced in this paper. They prove the existence and uniqueness of a vector of interbank payments that clears all liabilities under the assumption that all loans have to be either repaid in full or-in the case of a defaultthe remainder of funds will be split among the creditors. However, this liquidity-based algorithm assumes that all liabilities are cleared at the same time, regardless of their maturity. Elsinger et al. (2006) develop a version of this algorithm in which the notion of default is linked with negative equity, allowing for a solvency-based view of contagion, and embed it into a larger stress testing framework accounting for multiple risk factors. Elsinger (2009) extends the model to include equity participations and different seniority levels of debt. Suzuki (2002) independently developed a model that corresponds to the specification of Elsinger (2009), a contribution that has largely been overlooked in the literature for a long time. Rogers and Veraart (2013) extend the model to include liquidation costs and show that there exist incentives for mutual bailouts among banks. Fischer (2014) extends the model to include derivatives. Cifuentes et al. (2005) use the Eisenberg and Noe (2001) model to study the effects of deleveraging by leverage-constrained banks in a model using an asset fire sales model similar to the model presented in this paper.

While all the models above are based on the same underlying structure of the Eisenberg and Noe (2001) model, other alternatives have been developed. Furfine (2003) uses a simpler algorithm that imposes an exogenous recovery rate that is the same for all creditors, instead of an endogenously determined recovery rate as in the Eisenberg and Noe (2001) model. Caccioli et al. (2015) use a variant of that model to study the extent of contagion arising from direct contagion and overlapping portfolios, an approach that will be further refined in this study. Battiston et al. (2012) develop a popular contagion metric called DebtRank, which assumes that contagion occurs before creditors enter into default. Barucca et al. (2016) develop a comprehensive framework that encompasses both DebtRank and the Eisenberg and Noe (2001) model as special cases. Other contributions on the quantification of contagion effects include Upper and Worms (2004), Degryse and Nguyen (2007) and Cont et al. (2013). Upper (2011) provides a good overview of many of these approaches, and Caccioli et al. (2018) provide a more recent review. There also exists a rich literature studying fire sales alone, without the added contribution contagion effects from bilateral exposures. Shleifer and Vishny (2011) provide an overview of this literature, and Greenwood et al. (2015) provide an application of such a model to European banks. Clerc et al. 
(2016) present a qualitative framework of different effects that should be considered, including not only direct contagion and fire sales but also interactions between funding and market illiquidity, as discussed by Brunnermeier and Pedersen (2009).

There are relatively few articles studying the behavioural aspects of contagion beyond the mechanical aspects of exposure write-downs. Leitner (2005) shows that the threat of contagion can have positive effects as it provides incentives for banks to provide mutual insurance. Rogers and Veraart (2013) arrive at a similar conclusion using a model based on the Eisenberg and Noe (2001) framework. Halaj and Kok (2015) on the other hand study price formation in a game-theoretic model of network evolution. Aymanns and Farmer (2015) study the impact of leverage targets such as those imposed by Basel regulations on the cyclical dynamics of the financial system. Berardi and Tedeschi (2017) show how banks' business strategies affect the topology of the interbank network and, as a consequence, its systemic risk properties.

Following the finding of Allen and Gale (2000), several authors have investigated the relationship between the network structure and the contagion behaviour. Allen and Gale (2000) showed that a sparsely connected network may be more prone to contagion than a fully connected one thanks to diversification effects. Furthermore, it should be noted that in the complete absence of an interbank network the risk of contagion via this channel is also zero. This reasoning suggests that there should exist a non-monotonous relationship between connectivity and contagiousness: low risk for low and high levels of connectivity and high risk for medium levels. Nier et al. (2007) indeed find such a non-monotonous relationship for connectivity. Iori et al. (2006) further find that this non-monotonicity depends on heterogeneity among banks. Lenzu and Tedeschi (2012) study the contagion properties of different network topologies in a model with endogenous network formation. They provide further evidence that 'small-world' networks, where many nodes have few connections and few nodes have many connections, exhibit higher systemic risk. Elliott et al. (2014) study a linearized version of the model of Eisenberg and Noe (2001) and find a similar non-monotonous relationship.

Other studies on contagion properties include Gai and Kapadia (2010), who use methods from complex network theory to show that interbank markets exhibit a 'robust-yet-fragile' property: the general risk of contagion is low, but in the case a cascade occurs, it may affect large parts of the system. Teteryatnikova (2014) builds on this work and shows that networks with a 'tiered' structure, i.e. with a few highly connected central institutions and a large periphery of lowly connected institutions, are less prone to contagion. Boss et al. (2004), in one of the first comprehensive empirical studies on financial networks, show that real-world financial networks (in this case of the Austrian banking system) exhibit such a tiered structure. Poledna et al. (2015) look at the multi-layer dimension of contagion: using Mexican data, they find that contagion effects are super-additive with respect to different network layers (such as direct exposures and secularizations). This finding can be understood intuitively: consider a network of three banks and two layers of financial exposures. Assume that bank A and $\mathrm{B}$ are only connected on one layer of the network, B and C only on the other layer, and $\mathrm{A}$ and $\mathrm{C}$ not all. Now if contagion effects are modelled separately for different layers, then there is no possibility for a shock to bank A to ever affect bank $\mathrm{C}$. If all layers are viewed together, however, a shock to bank A might reach bank $\mathrm{C}$ via bank B. Thus, looking at several network layers simultaneously increases the possible range 
of contagion effects that can be considered, an effect that has also been observed by Bargigli et al. (2013) using Italian data.

\section{Model framework}

In this section, I will present a model that allows to study the channels of direct contagion and different components of overlapping portfolios both in isolation and when they are jointly active. The different channels that are considered are direct exposures, correlated losses, fire sales and mark-to-market effects. The channel of direct exposures describes how an initial shock that renders one or more institutions insolvent has the potential of creating a default cascade because the losses at an insolvent institution have to be borne proportionally by its creditors. Without liquidation costs, such a cascade-while leaving the consolidated value of the system unchangedamplifies the number of insolvent institutions and leads to a deflation of book values. Overlapping portfolios pose multiple threats to financial stability, namely through correlation of losses, through an exacerbation of fire sale losses and through markto-market effects. Fire sale losses are incurred when illiquid assets are liquidated in a resolution-these losses can be greatly amplified when multiple institutions holding similar assets are forced to sell onto the same markets. Mark-to-market accounting can foster the vicious circle of higher losses, leading to more defaults by forcing even non-defaulting institutions to recognize depressed asset prices. A similar model was used in Siebenbrunner et al. (2017). The main difference to the model presented herein is that Siebenbrunner et al. (2017) assumed a zero payoff from one bank that is subject to an idiosyncratic shock, whereas the payoffs herein are computed the same way for all banks, as the residual assets after a shock.

\subsection{Definition of a financial system}

The financial system is modelled as a set $\mathscr{N}=\{1, \ldots, n-1\}$ of financial institutions (henceforth 'banks'), and a 'sink node' with index $n$ that captures all connections that go outside the financial system considered, e.g. to the real economy or to other institutions in other countries. The bilateral loans between the banks are captured in a loan matrix $L \in \mathbb{R}_{+}^{n \times n}$, where $L_{i, j}$ represents the liabilities of bank $i$ towards bank $j$. All liabilities that are not owed to other banks (e.g. customer deposits) are captured as liabilities to the sink node, which ensures that the total liabilities of each bank are given by the row sum $\bar{p}, \bar{p}_{i}=\sum_{j=1}^{n} L_{i j}$. The sink node is assumed not to have any liabilities $\forall i: L_{n, i}=0$. The framework could of course be extended to include the balance sheets and liabilities of all other economic agents, perhaps aggregated at the sector level, but this is beyond the scope of this study [see e.g. Gray and Malone (2008) for a discussion of related approaches]. The notion that one bank's liabilities are-to some extent-assets of other banks is captured by a matrix $\Pi \in[0,1]^{n \times n}$ of relative liabilities, giving the fraction of total liabilities $\bar{p}_{i}$ that each loan $L_{i j}$ represents: ${ }^{1}$

\footnotetext{
1 This setup is based on earlier work by Eisenberg and Noe (2001). Table 3 in "Appendix" presents an overview of the variables used.
} 


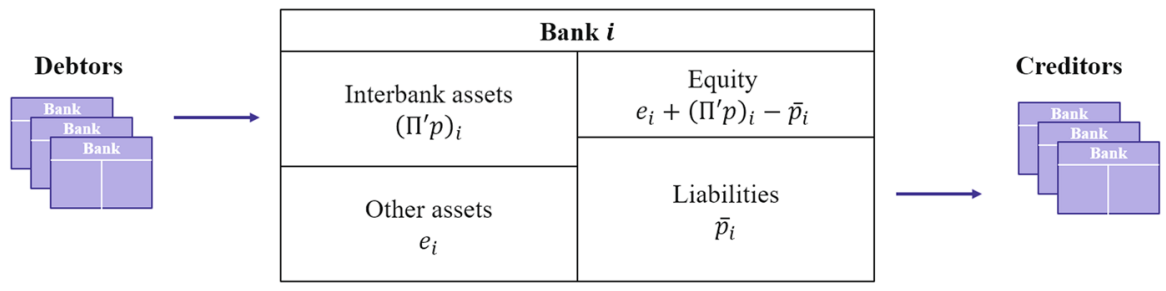

Fig. 1 Stylized balance sheet

$$
\Pi_{i j}= \begin{cases}\frac{L_{i j}}{\bar{p}_{i}} & \text { if } \bar{p}_{i}>0 \\ 0 & \text { otherwise }\end{cases}
$$

Regarding the asset side, banks are considered to hold two types of assets: external assets, which represent all on-balance items that are not intra-system claims and are captured by the vector $e \in \mathbb{R}_{+}^{n}$ and interbank assets. The value of interbank assets depends on how much each debtor bank is able to repay: solvent banks repay all their liabilities in full, while insolvent banks split the remaining value of their assets minus any liquidation costs proportionally among their creditors. For a given payment vector $p \in \mathbb{R}_{+}^{n}$, the value of interbank assets is given by $\Pi^{\prime} p \in \mathbb{R}_{+}^{n}$ (Siebenbrunner et al. 2017). Figure 1 shows the structure of such stylized, interlinked balance sheets.

The model is best understood by noting that the balance sheet equation can be written as:

$$
\text { Equity }=\text { Assets }- \text { Liabilities }=e_{i}+\left(\Pi^{\prime} p\right)_{i}-\bar{p}_{i} \text {. }
$$

Note that the original model by Eisenberg and Noe (2001) was intended for payment systems and thus had a slightly different interpretation of the variables. The balance sheet interpretation as described above was introduced by Elsinger et al. (2006).

\subsection{Direct contagion effects}

Whenever all firms in the system are solvent, the system described above is easy to solve, as the value of all interbank assets is simply given by the vector $\Pi^{\prime} \bar{p}$. However, once a bank that has received loans from other banks enters into default, the value of its assets is no longer sufficient to cover its liabilities, and the resulting losses have to be borne by its creditors. This may lead to cascades of failures, as described by Allen and Gale (2000) in their seminal contribution. If circles exist in the network of bilateral loans, the cascade may reach a debtor of an initially defaulted bank, creating a simultaneity problem for finding the correct value of all interbank assets. Cycles are a common phenomenon in real-world interbank networks (Thurner et al. 2003) and are also present in the data set used in this study.

Eisenberg and Noe (2001) show that under mild regularity conditions, there exists a unique solution for the asset values called the clearing payment vector $p^{*}$ and provide an algorithm to compute this vector. Under the clearing payment vector, all 
solvent nodes repay their obligations in full and all insolvent institutions pay the sum of their illiquid assets plus the remaining value of their interbank assets:

$$
p_{i}^{*}= \begin{cases}\bar{p}_{i} & \text { if } \bar{p}_{i} \leq e_{i}+\left(\Pi^{\prime} p^{*}\right)_{i}(\text { i.e. bank } i \text { is solvent }) \\ e_{i}+\left(\Pi^{\prime} p^{*}\right)_{i} & \text { otherwise }\end{cases}
$$

\subsection{Asset fire sales}

I describe the effects of asset fire sales as the liquidation costs associated with selling a large portfolio of assets onto less than perfectly liquid markets, as is common in the literature (Cifuentes et al. 2005). If defaulted banks have to liquidate their portfolio of assets to satisfy their obligations, such costs will amplify the losses for creditors. Note that under the definition of the clearing payment vector given above, creditors of defaulted banks receive the full amount of the current book value of illiquid assets plus the recovery amount of interbank assets; hence, there are no costs of liquidation. Rogers and Veraart (2013) provide an augmented version of the framework of Eisenberg and Noe (2001) that accounts for recovery values $\alpha \in[0,1]$ for illiquid and $\beta \in[0,1]$ for interbank assets. Rogers and Veraart (2013) show that there exist a least and a greatest fixed point of the map:

$$
\Phi(p)_{i}= \begin{cases}\bar{p}_{i} & \text { if } \bar{p}_{i} \leq e_{i}+\left(\Pi^{\prime} p\right)_{i} \\ \alpha e_{i}+\beta\left(\Pi^{\prime} p\right)_{i} & \text { otherwise }\end{cases}
$$

Rogers and Veraart (2013) provide an algorithm to compute the greatest clearing vector $p^{*}=\Phi\left(p^{*}\right)$. If the defaults are not prevented through bailouts, the value lost through liquidation costs represents the total welfare loss (Rogers and Veraart 2013):

$$
\text { Welfare loss }=\sum_{\left\{i: p^{*}<\bar{p}\right\}}\left((1-\alpha) e_{i}+(1-\beta)\left(\Pi^{\prime} p^{*}\right)\right)
$$

In the remainder of this study, I will determine asset fire sale losses through the fraction of value lost on illiquid assets $(1-\alpha)$ and set the recovery rate for interbank assets $\beta=1$. I argue that the devaluation implied by $\beta<1$ overstates the amount of contagion losses, as the recovery rate for interbank claims is already determined through the clearing algorithm. A further reduction of repayment values would imply that the amount received by a creditor of a defaulted bank is less than what the defaulted bank pays to this creditor. This may in some situations lead to a negative value of the overall system, which is inconsistent with the assumption of limited liability underpinning the clearing algorithm of Eisenberg and Noe (2001) and Rogers and Veraart (2013).

Proposition 1 The equity value of the financial system is bounded below by zero if and only if the recovery value for interbank assets $\beta=1$ 
Proof Following Rogers and Veraart (2013), I define the equity value of a single bank as the surplus of assets over liabilities for solvent banks and 0 for insolvent banks:

$$
\mathscr{V}_{i}(p, e)= \begin{cases}\left(\Pi^{\prime} p+e-p\right)_{i} & \text { if } p_{i} \geq \bar{p}_{i} \\ 0 & \text { else. }\end{cases}
$$

Summing the equity values after contagion (i.e. Eq. 6 evaluated at the clearing payment vector $p=p^{*}$ ), we obtain:

$$
\begin{aligned}
\sum_{i=1}^{n} \mathscr{V}_{i}\left(p^{*}, e\right) & =\overbrace{\sum_{\left\{i: p_{i}^{*} \geq \bar{p}_{i}\right\}}\left(e+\Pi^{\prime} p^{*}-p^{*}\right)_{i}}^{\text {Solvent banks }}+\overbrace{\sum_{\left\{i: p_{i}^{*}<\bar{p}_{i}\right\}}\left(e+\Pi^{\prime} p^{*}-\left(e+\Pi^{\prime} p^{*}\right)\right)_{i}}^{\text {Defaulted banks }(0 \text { equity value })} \\
& \left.=\sum_{i=1}^{n}\left(e_{i}+\left(\Pi^{\prime} p^{*}\right)_{i}\right)-\sum_{\left\{i: p_{i}^{*} \geq \bar{p}_{i}\right\}}\left(p_{i}^{*}\right)+\sum_{\left\{i: p_{i}^{*}<\bar{p}_{i}\right\}}\left(e+\Pi^{\prime} p^{*}\right)_{i}\right) \\
& =\sum_{i=1}^{n}\left(e_{i}+p_{i}^{*}\right)-\left(\sum_{\left\{i: p_{i}^{*} \geq \bar{p}_{i}\right\}}\left(p_{i}^{*}\right)+\sum_{\left\{i: p_{i}^{*}<\bar{p}_{i}\right\}}\left(e_{i}+\left(\Pi^{\prime} p^{*}\right)_{i}\right)\right) \\
& =\sum_{i=1}^{n}\left(e_{i}\right)+\sum_{\left\{i: p_{i}^{*} \geq \bar{p}_{i}\right\}}\left(p_{i}^{*}-p_{i}^{*}\right)+\sum_{\left\{i: p_{i}^{*}<\bar{p}_{i}\right\}}\left(p_{i}^{*}-\left(e_{i}+\left(\Pi^{\prime} p^{*}\right)_{i}\right)\right) \\
& =\sum_{i=1}^{n}\left(e_{i}\right)+\sum_{\left\{i: p_{i}^{*}<\bar{p}_{i}\right\}}\left(\alpha e_{i}+\beta\left(\Pi^{\prime} p^{*}\right)_{i}-\left(e_{i}+\left(\Pi^{\prime} p^{*}\right)_{i}\right)\right) \\
& =\sum_{i=1}^{n}\left(e_{i}\right)-\sum_{\left\{i: p_{i}^{*}<\bar{p}_{i}\right\}}\left((1-\alpha) e_{i}+(1-\beta)\left(\Pi^{\prime} p^{*}\right)_{i}\right)
\end{aligned}
$$

where we have used the fact that all rows of $\Pi$ corresponding to banks with positive liabilities sum to 1 by definition, and that $p_{i}^{*}=\alpha e_{i}+\beta\left(\Pi^{\prime} p^{*}\right)_{i}$ if $p_{i}^{*}<\bar{p}_{i}$ and $p_{i}^{*}=\bar{p}_{i}$ otherwise, as given by the model of Rogers and Veraart (2013).

With $\beta=1$, we have $\sum_{i=1}^{n} \mathscr{V}_{i}\left(p^{*}, e\right)=\sum_{i=1}^{n}\left(e_{i}\right)-\sum_{\left\{i: p_{i}^{*}<\bar{p}_{i}\right\}}\left((1-\alpha) e_{i}\right) \geq 0$. With $\beta<1$, this value can be negative when many banks are in default and/or the recovery value on outside assets is low, i.e. when:

$$
\sum_{i=1}^{n} e_{i}-\sum_{\left\{i: p_{i}^{*}<\bar{p}_{i}\right\}}(1-\alpha) e_{i}<\sum_{\left\{i: p_{i}^{*}<\bar{p}_{i}\right\}}(1-\beta)\left(\Pi^{\prime} p^{*}\right)_{i}
$$

Note that the result from Proposition 1 is a direct corollary of the results of Rogers and Veraart (2013). Since the fact that the condition of a non-negative equity value for the system implies a boundary on $\beta$ was not reported there, it is stated separately here. Another important corollary from their results is that for $\alpha=\beta=1$, which 
corresponds to the original model of Eisenberg and Noe (2001) and the direct contagion losses channel described in Sect. 3.2, contagion does not cause any reduction in the equity value of the entire system:

$$
\alpha=\beta=1 \Longrightarrow \sum_{i=1}^{n} \mathscr{N}_{i}\left(p^{*}, e\right)=\sum_{i=1}^{n} e_{i} \forall p^{*}
$$

\subsection{Overlapping portfolios}

Common exposures, i.e. multiple banks holding the same assets, expose the financial system to multiple risks: (i) increased correlation of losses under general macroeconomic shocks and (ii) an exacerbation of asset fire sale losses when defaulting banks sell their assets into the same markets, thus driving down market prices and raising liquidation costs endogenously. This effect may be further amplified through (iii) mark-to-market accounting regimes, whereunder even non-defaulting banks are forced to recognize liquidation losses on firesold assets, potentially leading to new defaults. I will discuss these effects in sequence below.

\subsubsection{Loss correlation}

If banks hold correlated assets, a general macro shock would manifest in a set of idiosyncratic shocks on the illiquid assets of each bank. Let this shock be represented by the diagonal matrix $\Gamma$, where the entry $\Gamma_{i i} \in[0,1]$ represents the percentage of the original value of the illiquid asset holdings of bank $i$ remaining after the common shock. Central Banks have designed extensive modelling frameworks for quantifying loss correlation under different macroeconomic scenarios, usually called stress testing models. In practice, the shock values $\Gamma_{i i} \in[0,1]$ could be obtained from such a stress testing model, giving a correlated shock for all banks that is consistent with the stress scenario. This would also allow incorporating the results of the model presented in this paper into a stress test model, to obtain contagion losses for all banks that are consistent with the stress scenario. The algorithm developed by Rogers and Veraart (2013) can then be generalized to study the effects of a common shock while taking into account contagion effects and liquidation costs. Let the clearing vector $p^{*, 1}(\alpha, \beta, \Gamma)$ be the fixed point of the map:

$$
\Phi_{1}(p)_{i}= \begin{cases}\bar{p}_{i} & \text { if } \bar{p}_{i} \leq e_{i} \Gamma_{i i}+\left(\Pi^{\prime} p\right)_{i} \\ \alpha e_{i} \Gamma_{i i}+\beta\left(\Pi^{\prime} \bar{p}\right)_{i} & \text { otherwise }\end{cases}
$$

Using this clearing vector $p^{*}(\alpha, \beta, \Gamma)$, the value after contagion losses of each bank following a shock to the value of the common asset can be computed as $\left.\mathscr{V}_{i}\left(p^{*}(\Gamma), \Gamma e\right)\right)$. In analogy to Rogers and Veraart (2013), the value of the system after contagion is then given by:

$$
\sum_{i=1}^{n} \mathscr{V}_{i}\left(p^{*}(\Gamma), \Gamma e\right)=\sum_{i=1}^{n} e_{i} \Gamma_{i i}-\sum_{\left\{i: p^{*}(\Gamma)_{i}<\bar{p}_{i}\right\}}(1-\alpha) e_{i} \Gamma_{i i}+(1-\beta)\left(\Pi^{\prime} p^{*}(\Gamma)\right)_{i}
$$




\subsubsection{Fire sale endogeneities}

The market dynamics for asset fire sale markets with endogenous price feedback loops merit deeper investigation and are thus presented in greater detail in Sect. 3.5. In this section, I will present the computation of contagion losses for general supply and demand functions. The functions used in this study and the proof of existence of and convergence to an equilibrium under this model are presented in Sect. 3.5.1.

Taking a supply function $s$ and a demand function $d$ as given, the equilibrium price for the common asset is expressed as a percentage of its original value given by the greatest fixed point $\alpha^{*, 1}(\Gamma)$ of the map:

$$
\Theta_{1}(\alpha)=d^{-1}\left(s\left(p^{*, 1}(\alpha, \beta, \Gamma), \Gamma\right)\right),
$$

where $p^{*, 1}(\alpha, \beta, \Gamma)$ is the clearing payment vector under loss correlation:

$$
p^{*, 1}(\alpha, \beta, \Gamma)=\Phi_{1}\left(p^{*, 1}(\alpha, \beta, \Gamma)\right) \text {. }
$$

The map $\Theta_{1}$ returns for any given recovery value $\alpha$ of the common asset a new market-clearing recovery value if interbank claims are evaluated under the clearing payment vector with liquidation costs $p^{*, 1}(\alpha, \beta, \Gamma)$. It calls the supply function $s(p)$, which maps a clearing payment vector to a quantity of supplied assets, and calls the inverse demand function $d^{-1}(s)$, which maps a given quantity to a new price, with this value. The fixed point thus corresponds to equating supply and demand on the firesale market, as discussed in greater detail for the particular model used in this study in Sect. 3.5. The equilibrium price for this model can be computed through a simple recursion $\alpha^{n+1}=\Theta_{1}\left(\alpha^{n}\right)$ initialized with $\alpha^{0}=1$, which converges to the greatest fixed point $\alpha^{*, 1}(\Gamma)$ in a finite number of steps, as shown by Siebenbrunner et al. (2017).

Note that the definition of $\Theta_{1}$ differs from the specification used by Cifuentes et al. (2005) because liquidation costs are considered only for defaulted banks. The rationale for this specification is given in Sect. 3.4.3.

\subsubsection{Mark-to-market losses}

If market prices for common assets are driven down through fire sales, this will affect all holders of the common asset operating under mark-to-market accounting standards, as they are forced to recognise losses due to lower market prices, regardless of their own solvency or whether they are exposed to the initially defaulted banks or not. This mechanism is often treated as identical to the fire sale endogeneities described above (Cifuentes et al. 2005). I will argue that these two channels should be considered separately, as the mark-to-market channel is the result of accounting standards and thus a-possibly unintended-consequence of regulation: it is possible that banks will default purely due to mark-to-market losses, increasing the amount of firesold assets and thus further increasing liquidation costs for all defaulting banks. Under historical cost accounting standards, there would be a time delay in the recognition of losses, allowing market prices to recover. Arguably, the majority of firesold assets will 
be financial assets, representing a claim on a stream of cash flows, whose fair value would be unaffected by price changes which are driven by market microstructure and liquidity. A mark-to-model accounting regime could thus potentially have similar effects as historical cost accounting standards in terms of eliminating this additional channel of contagion.

Technically, the adjustment process towards the equilibrium recovery value $\alpha^{*, 2}(\Gamma)$ under mark-to-market accounting is similar to the process described in 3.4.2, albeit under a more punitive clearing payment vector $p^{*, 2}(\alpha, \beta, \Gamma)$. Under this clearing vector, the devaluation of the common asset implied by $\alpha$ affects both solvent and insolvent banks (this specification is equivalent to the one in Cifuentes et al. (2005), albeit for a different market model — the market model used in this paper is presented in Sect. 3.5):

$$
\Theta_{2}(\alpha)=d^{-1}\left(s\left(p^{*, 2}(\alpha, \beta, \Gamma)\right), \Gamma\right),
$$

where

$$
p^{*, 2}=\Phi_{2}\left(p^{*, 2}\right),
$$

where

$$
\Phi_{2}(p)_{i}= \begin{cases}\bar{p}_{i} & \text { if } \bar{p}_{i} \leq \alpha e_{i} \Gamma_{i i}+\beta\left(\Pi^{\prime} p\right)_{i} \\ \alpha e_{i} \Gamma_{i i}+\beta\left(\Pi^{\prime} \bar{p}\right)_{i} & \text { otherwise. }\end{cases}
$$

Note that under this specification, mark-to-market accounting also creates additional losses from direct contagion, as more banks are being pushed into default.

\subsection{Market dynamics under asset fire sales}

As discussed in Sect. 3.4.2, overlapping portfolios create an interesting endogeneity for the price dynamics under asset fire sales (Sect. 3.3): the more banks are pushed into default, the more assets are being sold on the firesale market, exerting further downward pressure on market prices. Section 3.5.1 presents a model that captures those endogenous fire sale effects, Sect. 3.5.2 discusses its properties and Sect. 3.5.3 discusses how this model is calibrated to the available data.

\subsubsection{A model of price formation under asset fire sales with overlapping portfolios}

As in Siebenbrunner et al. (2017), I assume a demand function for the common asset which decreases in the amount of the common asset sold by all banks that are under liquidation. Examples of such demand functions can be found in the literature (Cifuentes et al. 2005; Caccioli et al. 2015). Here, I will assume that the haircut on the common asset is proportional to the share of the common asset held by those banks that cannot meet their obligations under a given payment vector, as expressed by the following inverse demand function $d^{-1}$. The inverse demand function returns a price $(\alpha)$ as 
a function of a supplied quantity $s$ and allows equating demand and supply on the firesale market:

$$
d^{-1}(s)=\alpha(s)=1-\kappa \frac{s}{\sum_{i=1}^{n} e_{i}},
$$

where $\kappa$ is a sensitivity parameter that governs how strongly prices react to changes in quantities. The reason why I choose to adopt this particular demand function is that has an appealing property that allows for an intuitive interpretation. In general, I argue that the liquidation value of an asset that no one is willing to buy should be equal to 0 . Under the demand function from Eq. 17, this would happen when $\kappa=1$ and all banks are in default. In general, the price will always drop to $1-\kappa$ when all banks are in default. This means that the parameter $\kappa$ can be interpreted as the share of potential buyers of firesold banking assets that are not part of the system. (Note that the price is expressed as a percentage of the original asset value.) In order for a firesale market to exist, I assume $\kappa>0$. Such external buyers could be banks in other countries (or simply not included in the sample, if only a subset of the entire system is considered) or other financial entities such as investment funds (Siebenbrunner et al. 2017). This property allows for calibrating the $\kappa$-parameter, as explained in Sect. 3.5.3.

The quantity of supply of firesold assets is given by the external assets of defaulted institutions (Siebenbrunner et al. 2017):

$$
s(p, \Gamma)=\sum_{\left\{i \in \mathscr{N}: \Gamma_{i i} e_{i}+\left(\Pi^{\prime} p\right)_{i}<\bar{p}_{i}\right\}} e_{i} .
$$

Recall from Sect. 3.4.2 that the clearing payment vector under asset fire sales $p^{*, 1}(\alpha, \beta, \Gamma)$ is a function of the equilibrium price $\alpha^{*, 1}$, which is defined as the greatest fixed point of the function $\Theta_{1}(\alpha)=d^{-1}\left(s\left(p^{*, 1}(\alpha, \beta, \Gamma), \Gamma\right)\right)$, which equates demand and supply. This fixed point can be computed through the $\alpha^{n}, n \in\{0,1, \ldots\}$ defined as:

$$
\alpha^{n+1}=\Theta_{1}\left(\alpha^{n}\right) .
$$

The convergence of this sequence to the greatest fixed point of $\Theta_{1}$ follows by noting that both $p^{*, 1}(\alpha)$ and $\Theta_{1}$ are monotone in $\alpha$, i.e. if $\tilde{\alpha} \leq \alpha$, then $p^{*, 1}(\tilde{\alpha})$ and $\Theta_{1}(\tilde{\alpha}) \leq \Theta_{1}(\alpha)$. These conditions allow applying Theorem 1 from Siebenbrunner et al. (2017), who established convergence for a different contagion model.

\subsubsection{Market dynamics}

The liquidation price of the common asset is determined through a tâtonnement process: following an initial shock $\Gamma$ which renders some banks insolvent, the clearing payment vector $p_{0}^{*}$ is evaluated at $\alpha_{0}=1$. Given that some banks were defaulting from the initial shock alone, $\exists i: \Gamma_{i i} e_{i}+\left(\Pi^{\prime} p^{*}\right)_{i}<\bar{p}_{i}$, this would lead to a positive supply of firesold assets. Through the inverse demand function, this would lead to a lower recovery value for the common asset $\alpha_{1}=\alpha\left(p_{0}^{*}\right)<\alpha_{0}$, potentially leading to 
Fig. 2 Tâtonnement process ( $\alpha$ is the price and $q$ the quantity of firesold assets)

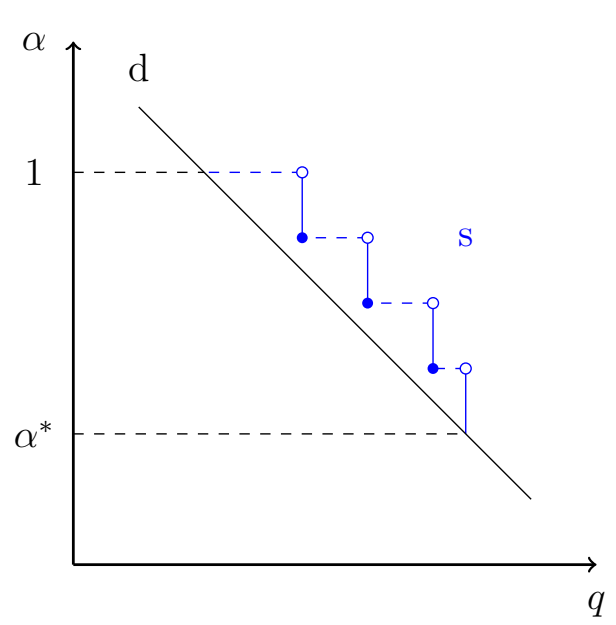

new defaults and new fire sales. This process continues until no more banks are being pushed into default. Figure 2 gives an overview of this process.

From Fig. 2, one can also observe two interesting properties of the firesale model:

(i) The supply and demand curve slope in the same (negative) direction:

$$
1 \geq \alpha^{\prime}>\alpha \geq 0 \Rightarrow d\left(\alpha^{\prime}\right) \leq d(\alpha) \wedge s\left(\alpha^{\prime}\right) \leq s(\alpha) \text {. }
$$

(ii) The supply function is discontinuous and price inelastic at all points except the discontinuities.

The second observation is readily confirmed by revisiting the definition of the supply function (Eq. 18). The first observation is confirmed by noting that the supply function can be expressed as a function of the price by inserting a clearing payment vector as defined by Eq. 13:

$$
s(\alpha)=s\left(p^{*, 1}(\alpha)\right)
$$

and by noting that for a higher price (recovery value) $1 \geq \alpha^{\prime}>\alpha \geq 0$ the clearing payment vector will be higher or equal to the original value $p^{*, 1}\left(\alpha^{\prime}\right) \geq p^{*, 1}(\alpha)$ by the definition of $\Theta_{1}$ (Eq. 12) and of the clearing payment vector. Furthermore, by the definition of $\Pi$ and of the supply function, a higher payment vector will result in a lower or equal amount of firesold assets: $s\left(p^{*, 1}\left(\alpha^{\prime}\right)\right) \leq p^{*, 1}(\alpha)$, showing that the supply function is monotonously decreasing in price (albeit not strictly). A negative slope sign for the demand function can be obtained directly by rewriting its definition (Eq. 17) as a function of price and noting that $\sum_{i=1}^{n} e_{i}, \kappa>0$ :

$$
d(\alpha)=(1-\alpha) \frac{\sum_{i=1}^{n} e_{i}}{\kappa} .
$$

A negative dependency of demand on price is common, but the same sign for the supply function is unusual: under normal circumstances, sellers do not increase their 


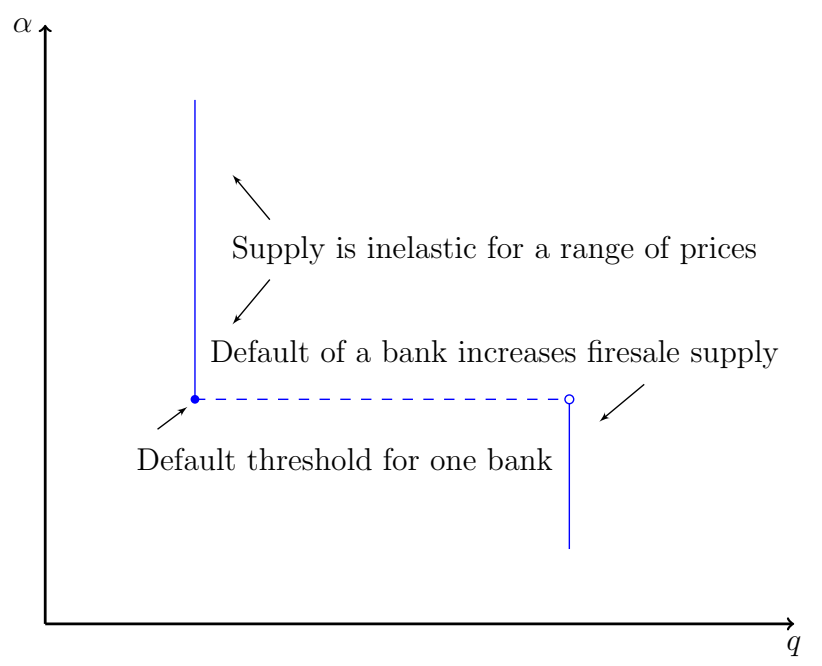

Fig. 3 Features of the supply function

offered quantities when prices fall. In the fire sale market model used in this study, however, sellers are forced into selling their assets when they reach their individual insolvency thresholds. The lower prices fall, the more sellers will reach those thresholds and thus increase the overall supply of firesold assets. Otherwise, no market participant has an incentive to sell their assets at a loss; hence, the supply function is generally inelastic, which is why the supply function is not strictly decreasing in price. Figure 3 provides an illustration of these features of the fire sale supply function. Taken together, these features also explain the second observation noted above that the supply function takes the form of a step function.

Another interesting observation that should be noted about the fire sale model is that the fixed point of $\Theta_{1}$ map is not necessarily unique. Looking at Fig. 2, this means that the supply function could be intersecting with the demand function more than once. This is the reason why the market equilibrium is defined as the greatest fixed point $\alpha^{*, 1}$ of the $\Theta_{1}$ map. Considering the features of the fire sale model described above, this assumption is readily motivated: for the same reason that the supply function is inelastic at all points except discontinuities, namely that no market participants have an incentive to sell more unless they are forced to, the tâtonnement process will stop once the first fixed point is reached (i.e. market equilibrium is achieved).

\subsubsection{Calibration}

The model contains a parameter- $-\kappa$ - that governs the price elasticity of demand and needs to be calibrated. As explained in Sect. 3.5.1, I interpret this parameter as the share that the external assets of the considered banking system $\left(\sum_{i=1}^{n-1} e_{i}\right)$ represents in the overall market for banking assets. I argue that the depth of this market should be governed by the features of the balance sheets of potential buyers, in particular by 
how many assets they could still purchase using external funding before they hit their own respective leverage targets.

A key task for calibrating the $\kappa$ parameter is thus to identify a relevant set of potential buyers. For the purpose of this article, I will work with a data set of Austrian banks (see Sect. 4.1). In line with Siebenbrunner et al. (2017), I argue that the main potential buyers for Austrian banking assets are other European banks outside of Austria. One may also argue that other financial institutions than banks, in particular investment funds such as hedge funds and private equity funds, could also be considered potential buyers. These are disregarded here because of difficulties of narrowing down the universe of investment funds to those who could be considered potential buyers of Austrian banks, and with obtaining relevant balance sheet information for them. The set of all European banks, on the other hand, could be considered too large, as many smaller institutions are unlikely to engage in cross-border acquisitions. The sample is thus reduced to major European banks with enough operational sophistication to consider such transactions. Given that these banks are usually also the more complex and larger institutions in their respective countries, I argue that the set of Significant Institutions, as defined by the European Central Bank within the Single Supervisory Mechanism (EU 2013) (excluding the Austrian institutions), provides a good proxy for the set of potential external buyers for Austrian banking assets (Siebenbrunner et al. 2017).

As noted above, the depth of the market is given by the sum of assets that all potential buyers could purchase before hitting their leverage targets. This quantity is called free leverage in Siebenbrunner et al. (2017) and computed as follows:

$$
\text { FreeLeverage }=\sum_{i \in \text { external Buyers }} \max \left(\frac{\text { Capital }_{i}-\text { Assets }_{i} * \theta}{\theta}, 0\right)
$$

where $\theta$ is a leverage target, expressed as a percentage of capital over assets. Under Basel-III regulations, banks are subject to leverage targets both for total and for riskweighted assets. So-called Pillar 1 targets are based on publicly available information from banks and largely common for all banks. (The composition of various additional capital buffers may vary for some sets of banks.) However, banks typically aim keep a safety buffer in excess of their Pillar 1 target, and such buffers may also be imposed by regulators (so-called Pillar 2 capital requirements, which are not publicly available). Using the correct leverage targets thus requires both data and judgment on the part of the modeller. I base my estimate of $\kappa$ on the calculations from Siebenbrunner et al. (2017), using the following formula:

$$
\kappa=\frac{\sum_{i=1}^{n-1} \text { Assets }_{i}}{\text { FreeLeverage }}
$$

As noted in Siebenbrunner et al. (2017), the specific leverage targets used are confidential. Calculations were performed for total and for risk-weighted assets, and both yielded estimates for $\kappa$ of around $50 \%$. I will thus assume a value of $50 \%$ for $\kappa$ in this article. 


\section{Quantifying the importance of different contagion channels}

In Sect. 3, I present a model that allows for computing the impact of a shock on the financial system for different contagion channels, and for separating their effects. The first question that I will ask about this model is how important those contagion channels are in relative comparison to each other. I will study this question using real-world data on the Austrian banking system (see Sect. 4.1).

\subsection{Data}

I study the model using quarterly data on the Austrian banking system for the period from the first quarter of 2008 to the third quarter of 2016. I use unconsolidated data, as interbank liabilities exist between unconsolidated entities and additional assumptions about loss sharing within banking groups would have to be made if one wanted to use consolidated data. The unbalanced panel comprises 814 banks on average. The following variables are constructed from the available data set:

\section{- Interbank network}

The liability matrix $L$ (those entries corresponding to interbank, not external liabilities) is constructed using data from the Central Credit Registry. Credit registry data are reported by all Austrian banks and cover all exposures exceeding a reporting threshold of $€ 350 \mathrm{k}$ across all asset classes on an obligor-basis per bank. Table 1 gives an overview of the reported asset classes. For consistency with the model, I use on-balance sheet exposures excluding ownership interests.

- External assets

External assets are computed indirectly, by subtracting the sum of interbank assets from total assets $A: e_{i}=A_{i}-\sum_{j} L_{j, i}$. Total assets are taken from the regulatory reporting system. As a sanity check, banks reporting greater on-balance interbank claims than their total assets are excluded from the calculations.

- External liabilities

External liabilities going to the sink node (i.e. outside the banking system) are again computed indirectly, as the difference between own funds $O$ and reported on-balance interbank liabilities: $L_{i, n}=A_{i}-O_{i}-\sum_{j=1}^{n-1} L_{i, j}$. Own funds are again taken from the Austrian regulatory reporting system; Table 2 gives an overview of the capital items used. In cases where no data are reported, own funds are taken from COREP reporting templates instead. As a sanity check, if the reported sum of equity plus interbank liabilities exceeds reported total assets, external liabilities are set to 0 and equity is reduced in order to balance the balance sheet.

Due to the highly confidential nature of these data, summary statistics for these variables cannot be presented.

\subsection{Impact function}

In order to quantify the importance of a contagion channel, I need to define a measure for computing its impact. Ideally, the measure should capture the welfare or social 
Table 1 Breakdown of exposures to be reported on the balance sheet. Source: Central Credit Register

\begin{tabular}{ll}
\hline Item & Exposure value \\
\hline Specialized lending & $\max$ (Lines of Credit, Drawdown) \\
Ownership interests & Drawdown \\
Short-term interbank exposures up to 1 year & Drawdown \\
Long-term interbank exposures longer than 1 year & Drawdown \\
Revolving available credit & $\max ($ Lines of Credit, Drawdown) \\
Non-revolving credit facilities and loans & $\max$ (Lines of Credit, Drawdown) \\
Lease receivables & $\max$ (Lines of Credit, Drawdown) \\
Securitized exposures & Drawdown \\
Trustee loans & $\max$ (Lines of Credit, Drawdown) \\
\hline
\end{tabular}

Table 2 Breakdown of capital items . Source: Regulatory reporting system

\begin{tabular}{ll}
\hline Official German naming & Translation \\
\hline Ergänzungskapital & Supplementary capital \\
Gezeichnetes Kapital & Committed capital \\
Kapitalrücklagen & Capital reserves \\
Gewinnrücklagen & Earnings reserves \\
Haftrücklagen & Contingency reserves \\
Unversteuerte Rücklagen & Untaxed reserves \\
Verlustvortrag & Retained losses \\
Gewinnvortrag & Retained earnings \\
\hline
\end{tabular}

losses induced through the contagion effects. However, as noted in the discussion of Theorem 1, it is not necessarily straightforward to define such welfare losses, as for some configurations the consolidated value of the financial system is simply given by $\sum_{i=1}^{n} e_{i}$. Since this quantity does not change under different clearing payment vectors, there are no immediate welfare losses due to direct contagion effects if one looks only at the financial system as a whole.

Where losses can indeed be observed, however, is at the disaggregate level of individual banks. These losses also correspond to the amount at risk for an outside entity that would have to perform a bailout. I thus argue that the sum of disaggregate losses serves as a good impact measure from the viewpoint of a policy maker who wants to design financial regulation in order to safeguard both financial stability and public finances. I will consider the impact of a shock as the sum of losses incurred across all banks in the system, normalized by the sum of total assets in the system (in order to control for fluctuations in loss amounts that are simply due to changes in the overall size of the system):

$$
\eta(a, p)=\frac{\sum_{i} e_{i}-a_{i}+\Pi^{\prime}(\bar{p}-p)_{i}}{\sum_{i} e_{i}+\Pi^{\prime}(\bar{p})_{i}},
$$


where $e$ again represents the vector of external assets and $\bar{p}$ the vector of total liabilities. $a$ represents the remaining value of external assets after a shock that is evaluated and $p$ the payment vector.

\subsection{Loss correlation}

I will now describe in sequence how the above models for different contagion channels can be used with this measure of systemic risk. First, I need to account for the correlation of losses. As described in 3.4.1, the matrix $\Gamma$ may contain individual shocks for each bank, allowing to study both idiosyncratic and correlated shocks. Consider a perfectly idiosyncratic shock that wipes out the entire value of the illiquid asset holdings of one bank. The corresponding entry in the shock matrix would be $\Gamma_{i i}=0$ or, more generally, $\Gamma_{i i}=\gamma$, where $i$ is the bank affected by the shock and $\gamma$ is the remaining value of the illiquid asset holdings after the shock. Now assume that the pair-wise correlation between bank $i$ 's illiquid asset holdings and any other bank's holdings is equal to $\rho$ for all banks. This framework allows for interpolating between a strictly idiosyncratic and a perfectly correlated shock for different shock magnitudes:

$$
\Gamma(\gamma, \rho, i)_{j k}= \begin{cases}\gamma & \text { if } j=k=i \\ 1-(1-\gamma) \rho & \text { if } j=k \neq i \\ 0 & \text { otherwise. }\end{cases}
$$

Figure 4 shows a plot of the impact function $\frac{\sum_{i=1}^{n} \eta(\Gamma(\gamma, \rho, i) e, \bar{p})}{|\mathscr{N}|}$ averaged across all banks in the sample and points in time. As can be seen, the impact of idiosyncratic shocks in the absence of correlation is practically zero, even for very high shocks. As correlation increases, impact increases in a rather linear fashion. However, it would be premature to draw any conclusions on the impact of loss correlation from this finding, as it has to be kept in mind that the parameter $\rho$ substantially increases the overall sum of losses in the system. The purpose of presenting this graph is rather to make the impact of any assumptions on the behaviour of common shocks transparent, which should be kept in mind when considering the impact of other contagion channels. As noted before, such correlations could practically be obtained from stress testing models. The model presented in this paper acts as a natural extension for such stress testing models, allowing to include components of systemic risk. For this reason, I will focus on contagion effects other than loss correlation in the following analyses and set $\rho=1$, under which the matrix $\Gamma(\gamma)=\Gamma(\gamma, 1,1)$ will be equal for all banks. The results presented in the remainder of the paper thus correspond to a common shock for all banks (but note that the framework allows computing contagion losses for arbitrary correlations of banks' assets).

\subsection{Assessing different contagion channels}

In the following, I will give a list of different combinations of contagion channels that can be evaluated using the framework introduced in Sect. 3. 


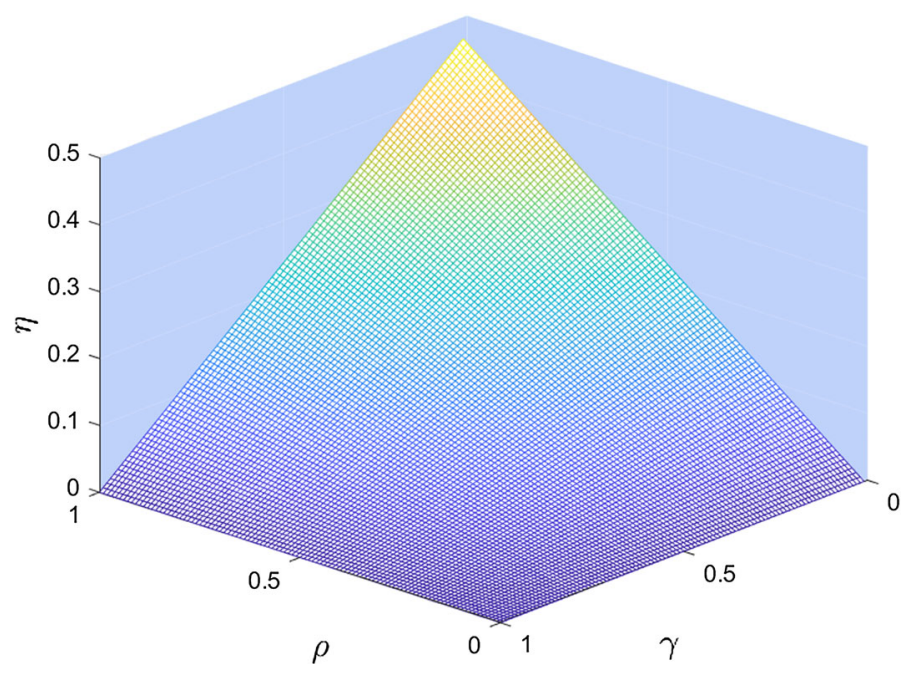

Fig. 4 Impact of common and idiosyncratic shocks

(i) Common shock - benchmark

In Fig. 4, no effects from direct contagion, asset fire sales or marking-to-market were considered. Such a specification can serve as a benchmark, against which the additional losses from these channels can be measured. The benchmark will thus evaluate the impact function for:

$$
\eta(\Gamma(\gamma) e, \bar{p}), \quad \forall \gamma \in[0,1]
$$

(ii) Common shock + direct contagion

This specification extends the benchmark to include only the effects of direct contagion:

$$
\eta\left(\Gamma(\gamma) e, p^{*, 1}(1,1, \Gamma(\gamma)), \quad \forall \gamma \in[0,1] .\right.
$$

(iii) Common shock + asset fire sales

Another simple extension of the benchmark includes only effects from fire sales, without accounting for contagion and second-round effects:

$$
\eta(\alpha(\bar{p}, \Gamma(\gamma)) \Gamma(\gamma) e, \bar{p}), \quad \forall \gamma \in[0,1]
$$

(iv) Common shock + direct contagion + asset fire sales

Under this specification, the effects from direct contagion and asset fire sales are both active. This leads to second-round effects, as the adjustment towards the equilibrium will follow the tâtonnement process described in Sect. 3.5.2. Under this process, interactions between asset fire sales and direct contagion effects occur, as lower recovery values may lead to additional defaults, leading to additional fire sales, and so on. The impact function will be evaluated at the equilibrium: 


$$
\eta\left(\alpha^{*, 1}(\Gamma(\gamma)) \Gamma(\gamma) e, p^{*, 1}\left(\alpha^{*, 1}(\Gamma(\gamma)), 1, \Gamma(\gamma)\right)\right), \quad \forall \gamma \in[0,1]
$$

(v) Common shock + direct contagion + asset fire sales + mark-to-market

Under this complete specification, all effects from direct contagion, asset fire sales and mark-to-market accounting are considered jointly, leading to the most severe impact. The inclusion of mark-to-market accounting creates additional interactions, as liquidation losses now affect all banks, leading to additional defaults, leading to further fire sales, leading to further mark-to-market adjustments and so on. The impact function will again be evaluated at the equilibrium:

$$
\eta\left(\alpha^{*, 2}(\Gamma(\gamma)) \Gamma(\gamma) e, p^{*, 2}\left(\alpha^{*, 2}(\Gamma(\gamma)), 1, \Gamma(\gamma)\right)\right), \quad \forall \gamma \in[0,1]
$$

Note that other possible combinations, in particular with mark-to-market accounting, are not included for practical reasons. Mark-to-market effects do not have any impact in the model in the absence of asset fire sales, ruling out combinations with a common shock and/or direct contagion alone. Once asset fire sales are taken into account, it is still difficult to distinguish between the impact of mark-to-market accounting and Direct contagion, as the impact of the former is also driven by the default of banks. In practice, the impact of the two is not distinguishable quantitatively and thus only the impact of the full specification is shown.

\subsection{Results and analysis}

Using the data described in Sect. 4.1, I evaluate the impact functions for the different configurations numerically for a range of $\gamma \in[0.01,1]$ (recall that $\gamma$ is the remaining value of external assets under an external shock, as explained in Sect. 4.3).

Figure 5 plots the impact function specifications for different configurations of contagion channels as described in 4.4 averaged over all points in time from the first quarter of 2008 to the first quarter of 2016. The figure shows the size of the shock on the $x$-axis and the impact, expressed as a percentage of total assets in the system lost (as defined by $\eta$ ) on the $y$-axis. As can be seen from the chart, the 'full' configuration taking into account all channels generates the highest impact, followed by the configuration considering all channels except mark-to-market accounting. The configurations considering only direct contagion or asset fire sales on top of the common asset shock in isolation incur lower losses; their ranking, however, differs across shock levels: for lower shock levels, fire sales have the higher impact, whereas for higher shock levels, direct contagion effects dominate. Figure 11 in "Appendix" shows the same information for all points in time. Visually, the picture looks similar across time, and the evolution over time will be investigated in more detail later in this section.

The goal of this analysis is to quantify the importance of individual contagion channels. I consider the impact of a contagion channel as the additional losses that are incurred once that channel is active. Formally, I define an impact function:

$$
\zeta(\gamma)=\eta(\cdot 11, \cdot 12)-\eta(\cdot 21, \cdot 22)
$$




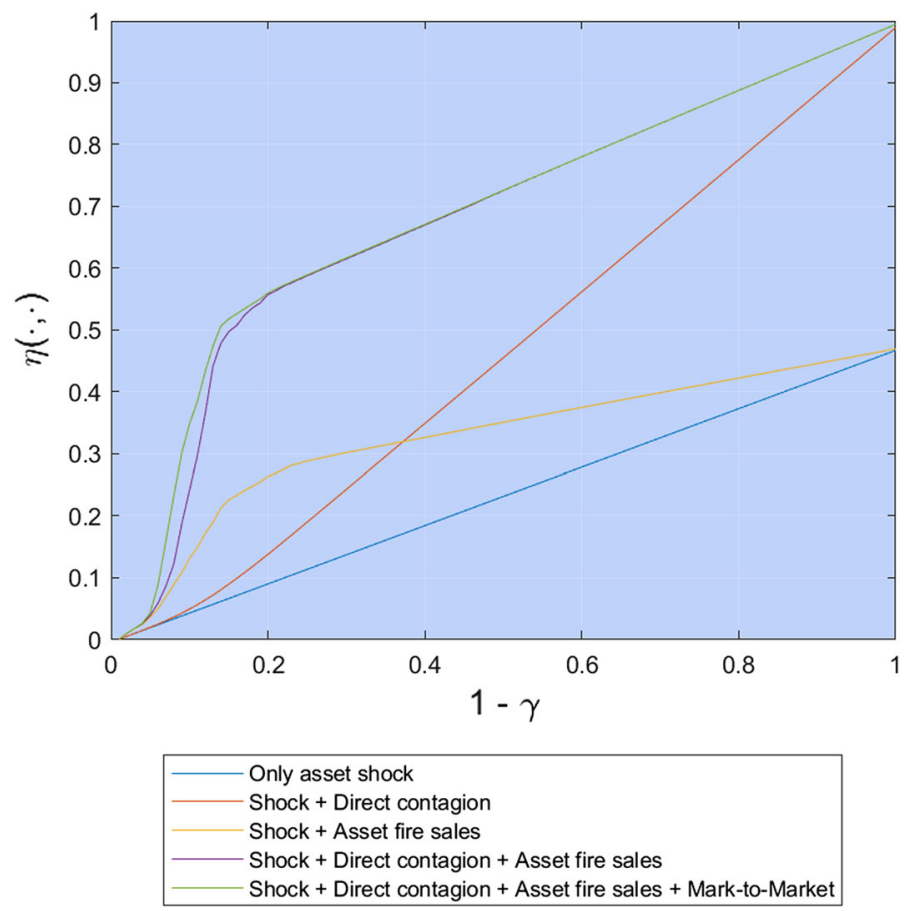

Fig. 5 Impact of different contagion channels (period 2008-2016)

where $\cdot 11, \cdot 12$ represents the specification including the channel in consideration and $\cdot 21, \cdot 22$ represents the same specification but excluding that particular channel. This means that I need to consider a benchmark case for each channel. As mentioned before, the common asset shock (configuration i) can serve as a benchmark for the two configurations looking only at direct contagion or asset fire sales in isolation (configurations ii and iii, respectively), giving the impact of each of those channels in the absence of the respective other channel. By comparing these with the configuration looking at both channels taken together (configuration iv), one can compute their additional impact in the presence of the respective other channel. The impact of markto-market accounting is then computed by comparing this configuration with the 'full' configuration (v) which includes all contagion channels.

I first consider the impact of individual contagion channels as measured by $\zeta$ averaged across all points in time. Figure 8 shows the impact for direct contagion effects. Direct contagion effects can be included into the benchmark specification as well as into the specification that includes the direct shock plus asset fire sales. Asset fire sales can be included in a similar manner; the results are shown in Fig. 9. The effects of mark-to-market accounting are plotted comparing the full specification with the specification that includes the common shock, direct contagion effects and asset fire sales, as shown in Fig. 10. As can be seen from those charts, both the asset fire sale and the mark-to-market channel quickly reach their respective maxima for relatively low shock levels $(1-\gamma$ below $20 \%)$ and decrease monotonously afterwards, whereby the impact of the asset fire sale channel decreases more slowly. The overall magnitude 
of the effect is of a greater scale for asset fire sales than for mark-to-market effects. Direct contagion effects, on the other hand, quickly reach a saddle point at a similar shock level as the other two channels in the presence of asset fire sales but increase almost linearly afterwards. In the absence of asset fire sale effects, their impact grows close to linearly over most of the range of shocks. The overall magnitude of the impact of direct contagion is on a similar scale as for the asset fire sales channel.

While Figs. 8, 9 and 10 give an overview of the impact of different contagion channels across different shock levels, it would be desirable to be able to compare them on a single metric which aggregates their impact over different shock levels. One way to approach this would be to ask how high the impact of a particular channel might be in the worst case:

$$
\zeta^{*}=\max _{0 \leq \gamma \leq 1} \zeta(\gamma)
$$

While the $\zeta^{*}$-metric gives a good insight into the maximum reach of a contagion channel, it has the disadvantage of comparing different channels for different shock levels. An alternative approach would thus be to consider the average impact over all shock levels:

$$
\bar{\zeta}=\int_{0}^{1} \zeta(\gamma) \mathrm{d} \gamma .
$$

Note that the introduction of a scalar metric for the impact of a contagion channel now allows to compare plot their impact over time instead of aggregated across all points in time, as has been done so far. Figures 6 and 7 plot the impact of the two impact metrics $\zeta^{*}$ and $\bar{\zeta}$ across different points in time. While the results differ to some extent across the metrics, some general observations can be made: (i) direct contagion effects generally dominate the other two contagion channels; (ii) asset fire sales generally dominate mark-to-market effects in terms of impact; and furthermore, (iii) the impact of the various contagion channels is rather stable across time, except for mark-tomarket effects, which show higher variance on the maximum impact metric $\zeta^{*}$.

\section{Conclusion}

The contagion model presented herein builds on the seminal model of Eisenberg and Noe (2001) and includes effects from overlapping portfolios using a firesale mechanism. The supply function of the firesale model was shown to have a negative slope, highlighting the extraordinary nature of market dynamics under fire sales. The firesale model endogenizes haircuts on external assets of insolvent banks, thereby extending the model of Rogers and Veraart (2013). It is shown that the haircut on interbank assets should be zero to avoid a paradox leading to negative equity values at system level despite limited liability of equity owners.

The model allows computing contagion effects emerging under a given shock. The impact of a single contagion channel can be obtained by comparing contagion effects before and after the channel is added to the model. Impacts for different shock levels 


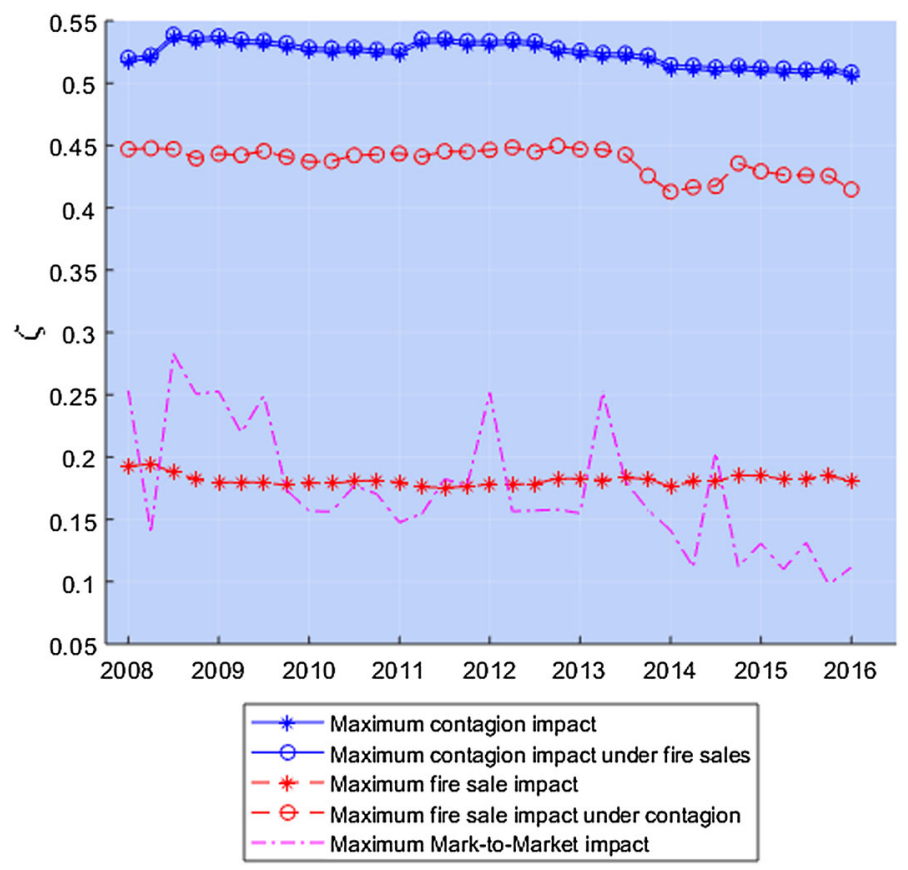

Fig. 6 Evolution of the maximum impact $\zeta^{*}$ of all contagion channels under different specifications

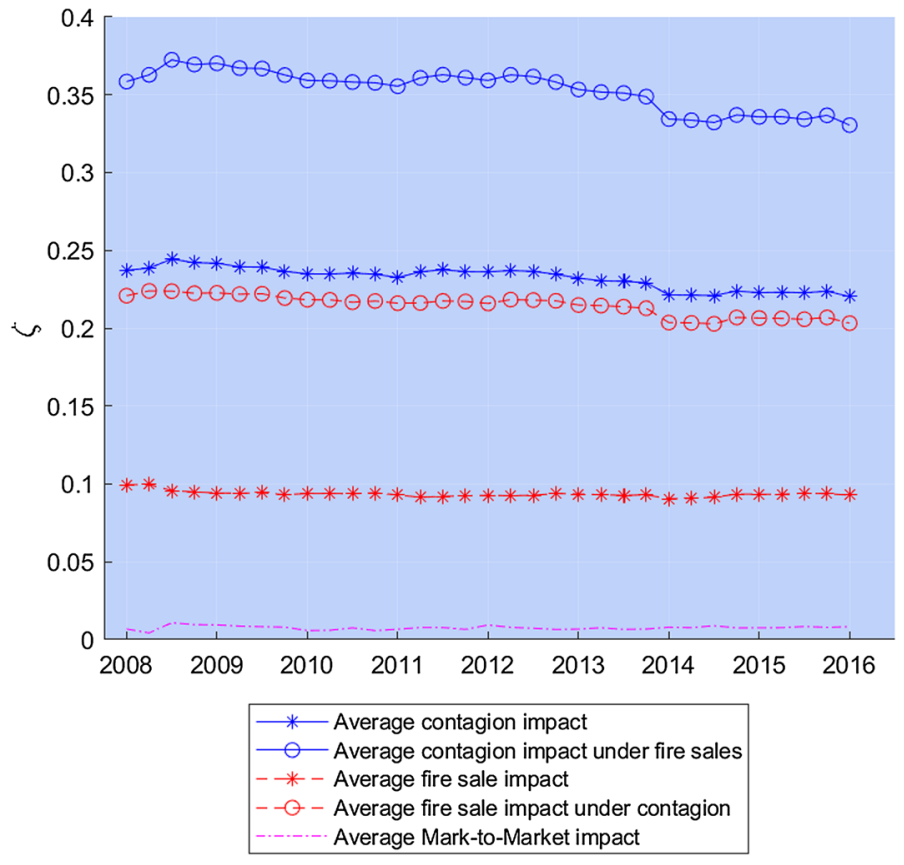

Fig. 7 Evolution of the average impact $\bar{\zeta}$ of all contagion channels under different specifications 
are aggregated into a single number describing each channel's contribution to systemic risk. For this analysis, a real-world data set covering the entire Austrian banking system over the period 2008-2016 was used. Results show that direct contagion effects have the highest impact, followed by asset fire sales and mark-to-market effects. Direct contagion effects should thus be a priority for regulators, and Siebenbrunner et al. (2017) have shown that current systemic risk regulations do indeed primarily address direct contagion effects.

This illustrates how the model presented in this paper can be used for assessing systemic risk regulations. Another important application is for computing contagion losses under a given macroeconomic scenario. These losses can be fed back into a stress test model, thereby including contagion effects in a stress test.

Open Access This article is licensed under a Creative Commons Attribution 4.0 International License, which permits use, sharing, adaptation, distribution and reproduction in any medium or format, as long as you give appropriate credit to the original author(s) and the source, provide a link to the Creative Commons licence, and indicate if changes were made. The images or other third party material in this article are included in the article's Creative Commons licence, unless indicated otherwise in a credit line to the material. If material is not included in the article's Creative Commons licence and your intended use is not permitted by statutory regulation or exceeds the permitted use, you will need to obtain permission directly from the copyright holder. To view a copy of this licence, visit http://creativecommons.org/licenses/by/4.0/.

\section{Appendix A: Variable overview}

\section{See Table 3.}

Table 3 Variable Definitions

\begin{tabular}{ll}
\hline Symbol & Description \\
\hline$n$ & Number of banks + 1 (for the sink node) \\
$\Pi$ & Liability matrix \\
$\bar{p}$ & Relative liability matrix \\
$p$ & Total liabilities \\
$p^{*}, p^{*, 1}, p^{*, 2}$ & Clearing payment vector, under fire sales (1) and mark-to-market accounting (2) \\
$e$ & External assets \\
$a$ & Remaining value of external assets after shock \\
$\alpha, \alpha^{*, 1}, \alpha^{*, 2}$ & Haircuts on external assets, equilibrium haircut under fire sales (1) and mark-to-market \\
$s$ & accounting \\
$d$ & Supply of firesold assets \\
$\kappa$ & Demand for firesold assets \\
$\rho$ & Sensitivity parameter for demand for firesold assets \\
$\beta$ & Correlation parameter \\
$\Gamma, \gamma$ & Haircut on interbank assets \\
$\eta$ & Shock to external assets \\
$\zeta, \bar{\zeta}, \zeta^{*}$ & Shock impact \\
\hline & Additive shock impact (average and maximum) \\
\hline
\end{tabular}




\section{Appendix B}

See Figs. 8, 9, 10 and 11.

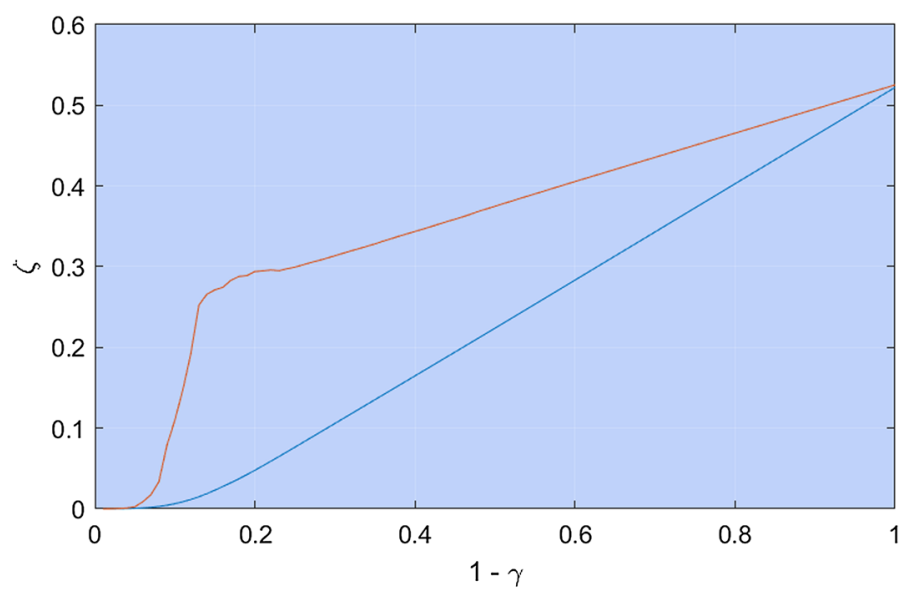

(Shock + Direct contagion) - (Only asset shock)

(Shock + Direct contagion + Asset fire sales) $-($ Shock + Asset fire sales)

Fig. 8 Impact of the direct contagion channel

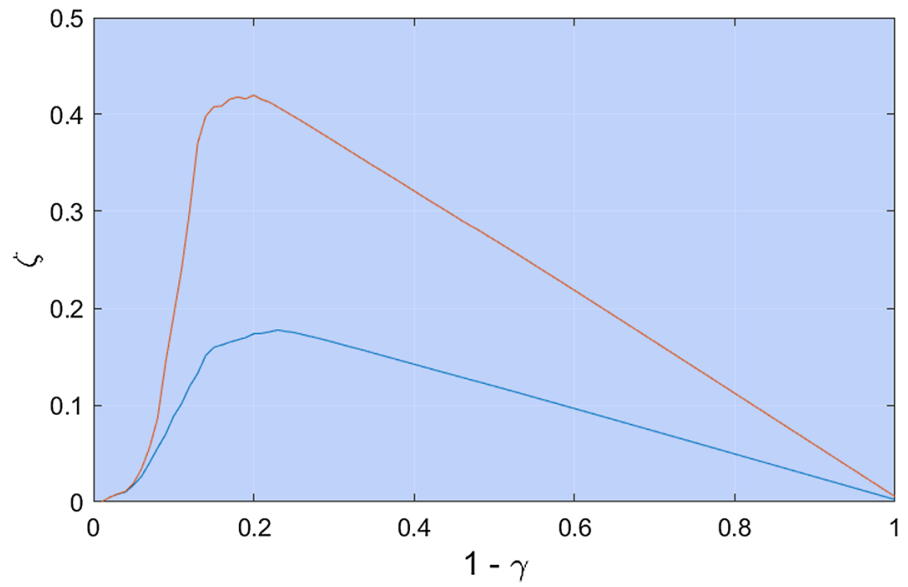

(Shock + Asset fire sales) - (Only asset shock)

(Shock + Direct contagion + Asset fire sales) - (Shock + Direct contagion)

Fig. 9 Impact of the asset fire sale channel 


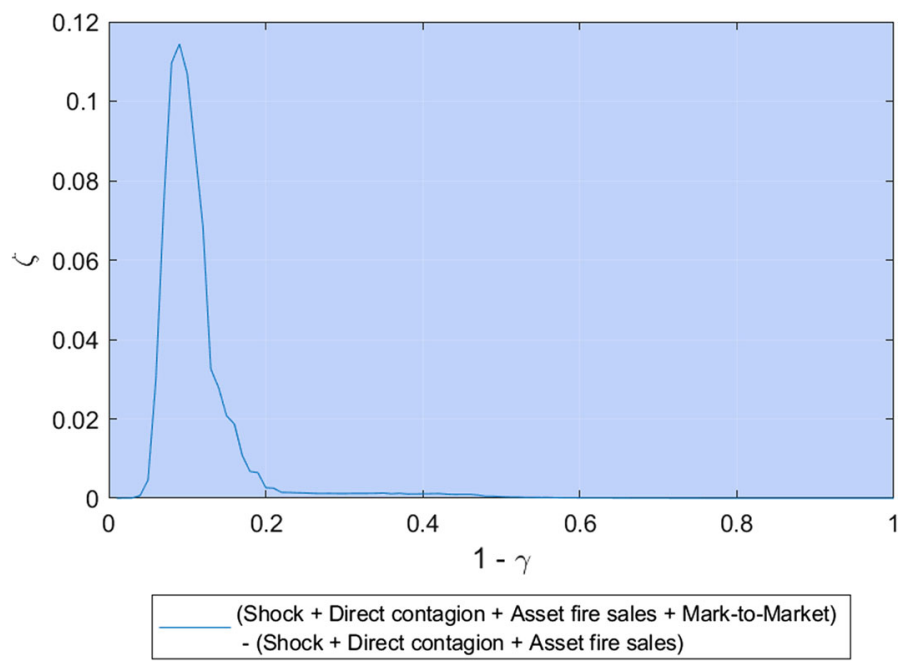

Fig. 10 Impact of the mark-to-market channel 

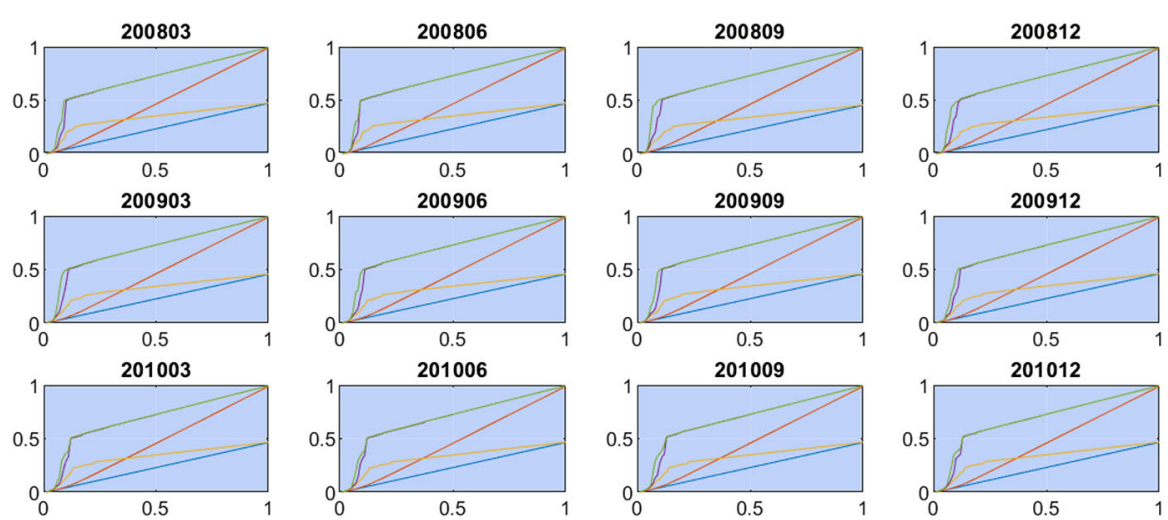

201103

201106
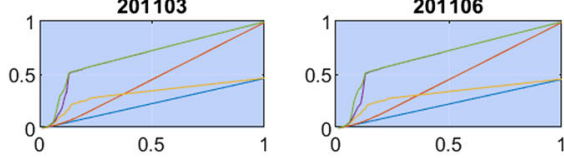

201203

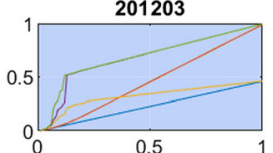

201206

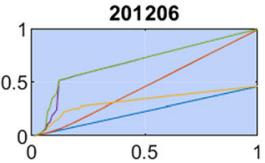

201303

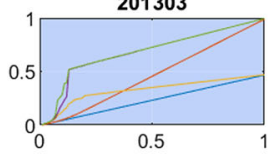

201306

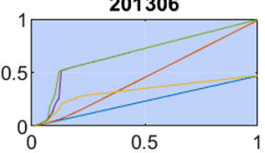

201406
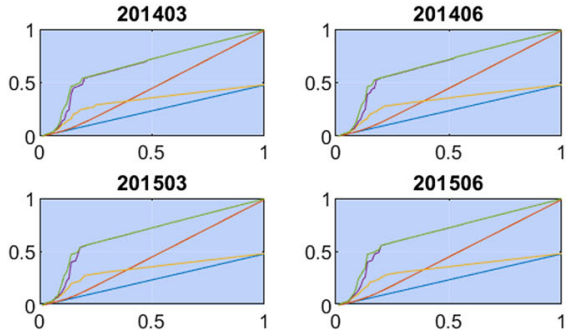

201109

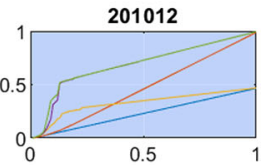

201112

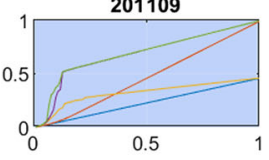

201209

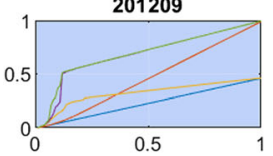

201309

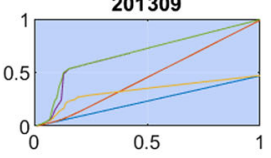

201409
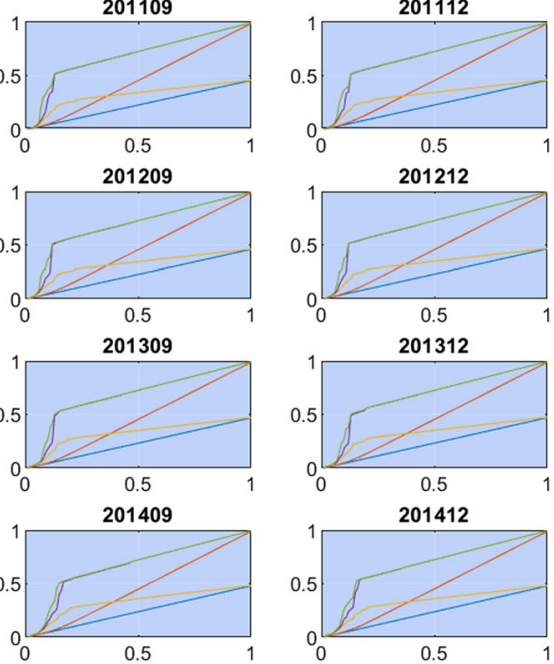

201412
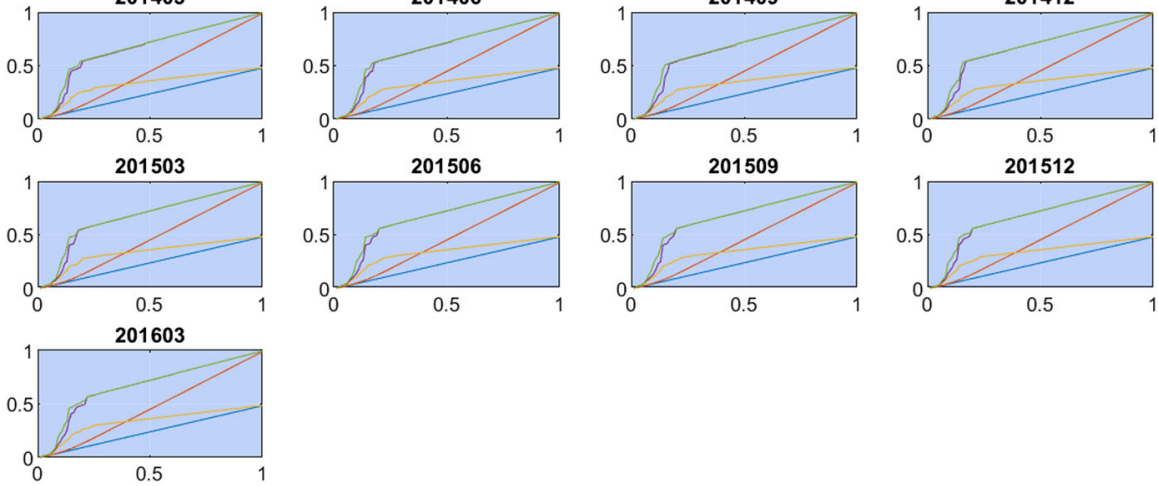

Fig. 11 Impact for different points in time 


\section{References}

Allen F, Gale D (2000) Financial contagion. J Polit Econ 108(1):1-33

Angelini P, Maresca G, Russo D (1996) Systemic risk in the netting system. J Bank Finance 20(5):853-868

Aymanns C, Farmer JD (2015) The dynamics of the leverage cycle. J Econ Dyn Control 50:155-179

Bargigli L, Infante L, Lillo F, Pierobon F (2013) The multiplex structure of interbank networks. Quant Finance 15(4):673-691

Barucca P, Bardoscia M, Caccioli F, D 'errico M, Visentin G, Battiston S, Caldarelli G (2016) Network valuation in financial systems. SSRN working paper

Battiston S, Puliga M, Kaushik R, Tasca P, Caldarelli G (2012) Debt-Rank: too central to fail? Financial networks, the FED and systemic risk. Sci Rep 2(541):1250058

Berardi S, Tedeschi G (2017) From banks' strategies to financial (in)stability. Int Rev Econ Finance 47(August 2015):255-272

BoE (2019) Stress testing the UK banking system: key elements of the 2019 annual cyclical scenario. Bank of England, London

Boss M, Elsinger H, Summer M, Thurner S (2004) The network topology of the interbank market. Quant Finance 4(6):677-684

Brunnermeier MK, Pedersen LH (2009) Market liquidity and funding liquidity. Rev Financ Stud 22(6):22012238

Caccioli F, Farmer JD, Foti N, Rockmore D (2015) Overlapping portfolios, contagion, and financial stability. J Econ Dyn Control 51:50-63

Caccioli F, Barucca P, Kobayashi T (2018) Network models of financial systemic risk: a review. J Comput Soc Sci 1(1):81-114

Cifuentes R, Ferrucci G, Shin HS (2005) Liquidity risk and contagion. J Eur Econ Assoc 3(2/3):556-566

Clerc L, Giovannini A, Langfield S, Peltonen T, Portes R, Scheicher M, Gabrieli S, Hansen H, Hodbod A, Kick H, Mazelis F, Vuillemey G (2016) Indirect contagion: the policy problem. ESRB occasional paper series, 9

Cont R, Moussa A, Santos EB (2013) Network structure and systemic risk in banking systems. In: Fouque J, Langsam J (eds) Handbook on systemic risk. Cambridge University Press, Cambridge, pp 327-368

Degryse H, Nguyen G (2007) Interbank exposures: an empirical examination of systemic risk in the Belgian banking system. Int J Cent Bank 3(2):123-171

DFAST (2019). Dodd-Frank Act Stress Test 2019: supervisory stress test results. Board of Governors of the Federal Reserve System

Diamond D, Dybvig P (1983) Bank runs, deposit insurance, and liquidity. J Polit Econ 91(3):401-419

EBA (2014) On the criteria to determine the conditions of application of Article 131(3) of Directive 2013/36/EU (CRD) in relation to the assessment of other systemically important institutions (O-SIIs). EBA guideline. European Banking Authority, Paris

EBA (2019) 2020 EU-wide stress test. European Banking Authority, Paris

Eisenberg L, Noe TH (2001) Systemic risk in financial systems. Manag Sci 47(2):236-249

Elliott M, Golub B, Jackson M (2014) Financial networks and contagion. Am Econ Rev 104(10):3115-3153

Elsinger H (2009) Financial networks, cross holdings and limited liability. OeNB working paper series

Elsinger H, Lehar A, Summer M (2006) Risk assessment for banking systems. Manag Sci 52(9):1301-1314

EU (2013) Council regulation (EU) no 1024/2013 of 15 October 2013 conferring specific tasks on the European central bank concerning policies relating to the prudential supervision of credit institutions

Feldkircher M, Fenz G, Ferstl R, Krenn G, Neudorfer B, Puhr C, Reininger T, Schmitz SW, Schneider M, Siebenbrunner C, Sigmund M (2013) ARNIE in action: the 2013 FSAP stress tests for the Austrian banking system. OeNB financial stability report, vol 26, pp 100-118

Fischer T (2014) No-arbitrage pricing under systemic risk: accounting for cross-ownership. Math Finance 24(1):97-124

Freixas X, Parigi B, Rochet J (2000) Systemic risk, interbank relations, and liquidity provision by the central bank. J Money Credit Bank 32(3(2)):611-638

Furfine CH (2003) Interbank exposures: quantifying the risk of contagion. J Money Credit Bank 35(1):111128

Gai P, Kapadia S (2010) Contagion in financial networks. Proc R Soc A Math Phys Eng Sci 466(2120):24012423

Gray D, Malone S (2008) Macrofinancial risk analysis, vol 433. Wiley, New York

Greenwood R, Landier A, Thesmar D (2015) Vulnerable banks. J Financ Econ 115(3):471-485 
Halaj G, Kok C (2015) Modelling the emergence of the interbank networks. Quant Finance 15(4):653-671

Heider F, Hoerova M, Holthausen C (2015) Liquidity hoarding and interbank market rates: the role of counterparty risk. J Financ Econ 118:336-354

Iori G, Jafarey S, Padilla FG (2006) Systemic risk on the interbank market. J Econ Behav Organ 61(4):525542

Leitner Y (2005) Financial networks: contagion, commitment, and private sector bailouts. J Finance 60(6):2925-2953

Lenzu S, Tedeschi G (2012) Systemic risk on different interbank network topologies. Physica A 391(18):4331-4341

Nier E, Yang J, Yorulmazer T, Alentorn A (2007) Network models and financial stability. J Econ Dyn Control 31(6):2033-2060

Poledna S, Molina-Borboa JL, Martinez-Jaramillo S, van der Leij M, Thurner S (2015) The multi-layer network nature of systemic risk and its implications for the costs of financial crises. J Financ Stab 20:70-81

Rochet J, Tirole J (1996) Interbank lending and systemic risk. J Money Credit Bank 28(4):733-762

Rogers L, Veraart LAM (2013) Failure and rescue in an interbank network. Manag Sci 59(4):882-898

Shleifer A, Vishny R (2011) Fire sales in finance and macroeconomics. J Econ Perspect 25(1):29-48

Siebenbrunner C, Sigmund M, Kerbl S (2017) Can bank-specific variables predict contagion effects? Quant Finance (forthcoming)

Suzuki T (2002) Valuing corporate debt: the effect of cross-holdings of stock and debt. J Oper Res Soc Jpn 45(2):123-144

Teteryatnikova M (2014) Systemic risk in banking networks: advantages of tiered banking systems. J Econ Dyn Control 47:186-210

Thurner S, Hanel R, Pichler S (2003) Risk trading, network topology and banking regulation. Quant Finance 3(4):306-319

Upper C (2011) Simulation methods to assess the danger of contagion in interbank markets. J Financ Stab 7(3):111-125

Upper C, Worms A (2004) Estimating bilateral exposures in the German interbank market: is there a danger of contagion? Eur Econ Rev 48(4):827-849

Publisher's Note Springer Nature remains neutral with regard to jurisdictional claims in published maps and institutional affiliations. 